\title{
Designing an Academic Skills Bridging Course for University Freshmen
}

\author{
Jing Hua Ye
}

\begin{abstract}
In the academic landscape, the dissertation of knowledge is of great importance to research-active academics. Yet the majority of students do not possess the necessary skills to effectively convey ideas in written format. Besides the lack of academic writing skills, plagiarism is another problem rife in academia and is rarely acknowledged. This problem is worsening with the increasing availability of technology. Apart from these two major problems, students often find that mastering mathematical problem-solving skills is arduous and leaves them without the confidence to complete math-intensive courses in their institution. Solid academic skills build a strong foundation for students' futures. Hence, a rigorous official preparation programme is needed to boost the educational attainment levels of disadvantaged groups of students. This paper charts the development of such a programme, entitled the Certificate in Academic Skills. A systematic approach, based on the backward design model, was utilized to develop this new programme, and resulted in the development of a programme capable of being delivered to all stakeholders. The CIPP model was used to evaluate this new curriculum. Based on this evaluation, we are confident that this vocational certificate will meet its intended goals and stand up well to further examination and scrutiny.
\end{abstract}

Index Terms-Curriculum design, curriculum process, curriculum evaluation, curriculum map.

\section{INTRODUCTION}

Across many different disciplines, academic writing has been consistently rated as being more and more important to success in undergraduate study; it is even more important to success after graduation. Over the past several years, it has become apparent that students entering the undergraduate programmes of STEM (Science, Technology, Engineering, and Mathematics) fields lack the necessary writing skills needed to become successful communicators. Students also may struggle to understand the characteristics of different categories of writing tasks. The majority of students do not possess the necessary skills to effectively communicate ideas in a written format. The substandard writing abilities of students have been increasingly triggering concern amongst lecturers.

From teaching to research publication, the internet has transformed the way higher education (HE) is done. The influence of the internet is everywhere. Across the English-speaking world, there is a growing concern that plagiarism is on the rise, in large part the result of easy access

Manuscript received March 9, 2019; revised August 3, 2019. This work was supported in part by the Teaching and Learning Unit (TLU) and the Computer Science Department in Cork Institute of Technology.

Jing Hua Ye is with the Cork Institute of Technology, Cork, Ireland (e-mail: jinghua.ye@cit.ie). to academic papers on the internet. A growing number of countries and international professional fraternities has identified plagiarism as research misconduct and, when students are involved, as academic misconduct when students are involved. Fostering high ethical standards within research environments requires increasing attention to international perspectives. Preventing plagiarism and promoting academic integrity is a challenge for institutions and universities globally.

Problem solving skills are essential in almost all disciplines and can be fostered through building up mathematical problem-solving skills. Academics in $\mathrm{HE}$ has expressed concern over the basic skills of secondary school students who, even after studying higher-level secondary school mathematics, still struggle with the mathematical aspects of their scientific degree courses.

Clear and effective communication skills in reading, speaking, and writing are required for every job and career. Therefore, an official and rigorous academic preparation programme is needed to boost the educational attainment levels of disadvantaged groups of students by cultivating the skills, knowledge, confidence, aspirations, and overall preparedness that are required to enroll in and succeed in college.

This paper mainly focuses on the process of applying an innovative instructional design model to construct a brand new educational programme that could serve as a Special Purpose Award. This educational programme is called the Certificate in Academic Skills, which encompasses three modules - Academic Writing for Novices, Introduction to Plagiarism, and Fundamental Problem-Solving Skills. In this paper, we also lay out the rationale and learning philosophy underpinning this design.

The curriculum philosophy will be covered in the following section. Curriculum design strategies will be covered in the case study section. This newly designed programme will be evaluated with a popular curriculum evaluation model in the evaluation section. This paper concludes with a reflection on the entire curriculum design process.

\section{LITERATURE REVIEW}

Atherton [1] states that the term 'curriculum' can refer to the overall content of what is to be taught, that it can also refer to the underlying principles of the approach to teaching and learning, and that it can embrace both by referring to the overall "what", "how", and "why" of teaching. [1] also built a two-dimensional model distinguishing four types of curricula: academic, vocational, mastery, and developmental. The objectives and usage of academic curricula are often very 
general. The vocational curriculum emphasizes using the material in order to do something else; its learning objective is not remembering or reproducing when assessed, but learning when best to use it. The competence-based curriculum is based on the mastery model where the task of education is to induct learners into an established body of knowledge and the curriculum designer knows what competence consists of and what performance criteria constitute. The developmental curriculum concerns quite advanced skills, of which the measure is "improvement" rather than the achievement of a particular level. In the real world, most teaching and learning contains a mixture of these types of curricula.

Kelly [2] defines curriculum as "All the learning which is planned and guided by the school, whether it is carried on in groups or individually, inside or outside the school." Finch [3] supports two important concepts, one is the central focus of a curriculum, which is the student, and the other is the breadth of learning experiences and activities associated with a curriculum. Curriculum development is "the process of defining, organizing, combining, and coordinating content so that it leads learners to the acquisition of knowledge, skills, and aptitude" [4]. It is "what" the student will learn, not "how" the learning will be accomplished. Instructional design is the latter.

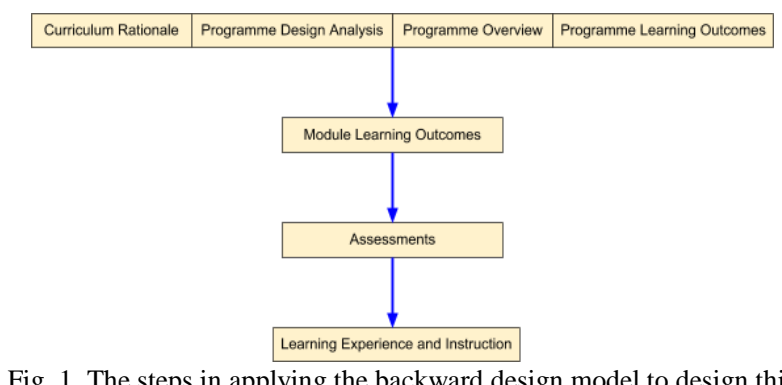

Fig. 1. The steps in applying the backward design model to design this certificate.

There are two popular polarized curriculum models - the product model, stemming from the work of Ralph Tyler [5], and the process model [6]. A variation of the technical scientific approach is the backward design model [7]. Compared to the forward design model, the backward model is more effective and puts student learning outcomes at the center; meanwhile, it offers lecturers the flexibility to structure both the learning experience and the evaluation tools used to gauge students' progress. This model is more a student-centered view than a content-centered view. In the non-scientific and non-technical approach, there are many different curriculum models. Barrow [8] describes the concept of problem-based learning as learning through the sweat of students' effort which in turn leads to their own understanding and the development of problem-solving skills. The ARCS model [9] contains four components - attention, relevance, confidence, and satisfaction. To create an optimal learning environment in which students would be motivated to learn, it is necessary to take these four components into consideration during the curriculum design. The ADDIE model [9] is a generic systematic step-by-step framework. This model focuses heavily on the process in which the learner will achieve set goals. It is time-consuming to use this model for developing a programme as all the phases are interrelated and a change in one phase may lead to reworking several others. Unlike traditional models, the Dick and Carey model [10] works through a series of ten steps towards a defined instructional goal. In this model, components are important to the success of students' learning and are integrated with each other.

\section{CASE STUDY}

We will exploit the backward design model, one of the product models, to design a brand new educational programme, entitled the Certificate in Academic Skills. It strongly focuses on the end product and its driving focus during the curriculum process is an emphasis on assessment Assessment is of great importance for directly impacting student learning [11]-[13]. This backward model is in line with the Competences in Education and Recognition Project [14]. The steps in applying this model are illustrated in Fig. 1.

\section{A. Stakeholders}

There would be several relevant stakeholders for this certificate. This certificate needs to support the overall mission of an institution. The mission of my institution, CIT, clearly states that it seeks "To provide student-centered, career-focused education and research for the personal, professional and intellectual development of the student and for the benefit of the broader society in the region and beyond". Another stakeholder would be the Irish awarding body HETAC (Higher Education and Training Awards Council). The naming convention for Special Purpose Awards is clearly outlined in HETAC's Policy and Draft Guidelines on Minor, Special Purpose and Supplemental Awards: "All Minor, Special Purpose and Supplemental awards at levels 7 to 10 with an ECTS credit volume under 60 credits to commence with the title 'CERTIFICATE"'. This programme complies with the naming convention required from HETAC. Other groups of stakeholders are students for whom this certificate would be designed, and the external validation panel. As this certificate is a brand new non-existing programme, once it runs successfully, another potential future group of stakeholders to consider would be similar competing programmes in other Irish educational institutions.

\section{B. Programme Design Analysis}

This certificate is a hybrid of teacher-centered and learner-centered learning. It would be delivered by academic experts who have a firm grasp of rhetorical styles, writing genres, and research skills, and who are professional English for Academic Purpose (EAP) teachers. This certificate will form a cornerstone for progressing to another level of academic success. It will sit at level 6 on the NFQ (National Framework of Qualifications). It fills a current void in all available programmes in the institution. It will only be targeted at freshmen or anyone else who does not have sufficient academic skills. Each module in this curriculum is mandatory and carries the same amount of ECTS (European Credit Transfer System) credit (10 credits). The total ECTS credit of this certificate will be 30 . Thus, learners will only 
receive "pass" or "fail" as their final result for this certificate". It will be delivered peer-to-peer two nights per week over one academic year. This certificate will act as a generic supplementary qualification for all major awards available in the institution. Students do not need to have any specific pre-entry requirements. It also will welcome recognition of prior learning (RPL) applications according to the institution's policy. This certificate possesses a generic standalone curriculum; hence, it is not connected to any other levels of any programmes in the institution.

\section{Ensuring Programme Quality Standards}

To ensure the certificate's quality standards, a cohort should be formed from relevant experts and stakeholders with the goal of upholding the quality of the curriculum established. Possible members of such a group tasked with maintaining quality of the certificate would be: professional accreditation experts, academic external examiners, the internal quality assurance group, an external liaison panel, employers. Such a cohort would be particularly useful to validate the quality of this certificate in the absence of a particular official well-known standard.

\section{Programme Learning Outcomes}

A programme learning outcome (PLO) is a statement of what a learner is expected to know, understand or be able to do on successful completion of the entire programme. The Quality Assurance Agency for Higher Education's (QAA's) benchmark statements contain threshold levels as well as other performance levels. Unfortunately, the QAA does not supply a standard for the academic skills field as it is an innovative programme. The National Qualifications Authority of Ireland (NQAI) has published a national framework of qualifications where a set of PLOs at each award level is defined. This certificate will follow the NFQ generic HE and training standard for level 6 to generate the PLOs.

Five PLOs are generated for this certificate. This reflects that it is a 30 credits programme running over one academic year and these PLOs take the restrictions of time and resources into account. These generated PLOs are as follows:

PLO1 (Knowledge Breadth): Have fundamental knowledge and understanding of academic skills in the areas of academic writing, plagiarism, and Math problem-solving skills.

PLO2 (Knowledge Kind): Possess a good understanding of Mathematics and its applications, various writing strategies, and plagiarism prevention.

PLO3 (Knowledge-how and Skill-selectivity): Confidently express and propose ideas, facts, approaches, and solutions for a well-defined Math application to others effectively in a narrative format with a good plagiarism prevention technique.

PLO4 (Competence Context): Have an appreciation of the importance of being a successful communicator with a high ethical standard in the academic environment.

PLO5 (Competence Role): Work effectively either independently or in a team.

\section{E. Module Learning Outcomes}

Module LOs focus on learning rather than teaching. They define what students must be able to do in order to pass the module. Each module LO should be transparent and determine the type of teaching planned. The verbs used to describe module LOs should strongly support this. Thus, we should carefully choose the verbs to be used by following Bloom's taxonomy [15], [16] to assist in composing a module LO. Consequently, we need to decide the type of learning to be achieved beforehand. Based on the rationale and analysis of this certificate discussed earlier on, it is clear that this certificate aims to be a programme with a combination of theoretical and practical focus. The LOs for modules in this certificate will sit at the bottom of Bloom's taxonomy centered on remembering, understanding, and applying.

Individual modules may have been integrated into different disciplines via different forms in various international universities, particularly academic writing modules and the mathematics problem-solving skills modules. Math problem-solving skills is a mature module and it has been set up as a standalone curriculum globally. To properly set up the LOs for individual modules in this certificate, we will review and reference these existing modules and adapt their LOs to align with our previous defined level of PLOs in this certificate.

Candidates are expected to not have any academic skills except fundamental Mathematics on entry. Therefore, this certificate only serves as an introduction to academic skills. Three modules are proposed for this programme; all are fundamental mandatory modules worth 10 ECTS credits and, therefore, there is a total of 30 credits for the level 6 award.

The five LOs of the Academic Writing for Novices module:

LO1: Paraphrase academic writing.

LO2: Practise different types of academic essays.

LO3: Sketch clear, varied, well-structured sentences with usage and mechanics conforming to standard edited English.

LO4: Organize a paper with a clear logical structure and cohesive, well-developed paragraphs.

LO5: Demonstrate an understanding of writing as a complex, recursive process whereby ideas are explored, developed, and communicated to a particular audience for a particular purpose.

The five LOs of the Academic Introduction to Plagiarism module are:

LO1: Define plagiarism.

LO2: Explain the benefits of appropriate referencing.

LO3: Explain how to acknowledge the work of other people.

LO4: Identify the difference between paraphrasing and plagiarizing and the difference between a citation and a reference.

L05: Employ various key skills such as how to cite, reference, paraphrase, and summarize to prevent plagiarism.

The four LOs of the Fundamental Problem-Solving Skills module are listed as follows:

LO1: Recognize that mathematics permeates the world around us.

LO2: Use appropriate mathematical concepts and skills to 
tackle problems in both familiar and unfamiliar situations including those in real-life contexts.

LO3: Use appropriate mathematical language in both oral and written explanations.

LO4: Monitor and reflect on the process of mathematical problem solving.

\section{F. Modules Assessments}

Assessments have a huge impact on how students learn, how much time they devote to their study, the concepts they comprehend and how widely they cover the curriculum [17]. In contrast to deep and surface learning, active learning encourages students to critically analyze and link learning to ensure better comprehension and retention of the material.

There are three primary perspectives on assessments: assessment of learning, assessment for learning, and assessment as learning [18]. Assessment of learning can be regarded as summative assessment; likewise, assessment for learning can be regarded as formative assessment. Formative assessment is the advocated system where multiple criteria are used in making judgments about the quality of student responses. It has less relevance for outcomes in which student responses may be appraised as correct or incorrect. It tends to generate feedback on performance to improve and accelerate learning. Students' understandings are progressively refined through feedback. Research literature has argued that formative assessment has key advantages for refining students' learning [19].

In the present teaching and learning system, there are three main unambiguously correlative components: the curriculum, teaching, and assessment tasks. These components should be integrated and fine-tuned to effectively support high-quality learning where there is a systematic approach to curriculum design that optimizes the conditions of quality learning. Constructive alignment (CA) [20] is such a system. It is also a framework where all teaching and learning activities and assessment tasks are properly in compliance with the LOs to be attained. Properly implemented CA can be leveraged to improve teaching and learning activity, where it subsumes forms of quality assurance that can often be counter-productive. Professor John Biggs [20] argues that if there is an alignment and a consistency between curriculum objectives, teaching and learning activities, and assessment tasks, then students will find it hard to "escape without learning".

We will adopt the combination of formative assessment and summative assessment to appraise students' performance on each module. Terminal written exams will be a means of summative assessment. This programme is also designed to give learners an opportunity to gain some hands-on experience with the technologies being introduced. In all modules, assessments will be constructively aligned with their LOs. Aside from the nature of the assessment, time constraints are another factor that force students to employ surface learning. It is important that assessments are balanced across the two semesters.

The assessment methods of the Academic Writing for Novices module are as follows:

Essay: Write an argumentative essay without bibliographies and references (35\% of total).
Assignment: Write different types of academic essay without bibliographies and references (35\% of total).

Terminal Exam: Required to identify and addresses errors in an academic text. Required to write an argumentative essay with a certain word limitation and choose one type of essay given in the paper and write it within certain word limits (30\% of total).

The assessment methods of the Introduction to Plagiarism module are as follows:

MCQ: Assess whether or not students have understood the key issues (20\% of total).

Essay: Write an essay with proper bibliographies and references (30\% of total).

Reflective Journal: Reflect on how to use various anti-plagiarism software tools and different prevention techniques to compose a plagiarism-free narrative $(50 \%$ of total).

The assessment methods of the Fundamental Problem-Solving Skills module are as follows:

Group Project: Employ different problem-solving skills to solve a real-life problem with a group of four people. Each group needs to give an oral presentation at the end of the term (35\% of total).

Portfolio: Self-reporting of problem-solving processes learned and employed, students can use group project as a case-study for this portfolio (35\% of total).

Terminal Exam: Required to apply different problem solving skills to solve a set of well-defined problems in a limited time ( $30 \%$ of total).

There is a great deal of research evidence proving that students under-perform in assessment tasks because of a failure to grasp the requirements [21]. For all the assessments, lecturers will present an exemplar and a preset rubric to clarify their expectations for the assessments. The lecturer for each module needs to be able to provide prompt feedback for students' submitted attempts and use various technologies to detect plagiarism, like Turnitin, and to speed up the feedback process, like audio feedback. For all writing assessments, lecturers will consider using peer-review and self-review strategies to diminish the volume of formative feedback. Students will gain an opportunity to view and learn from other people's perspectives and strategies through a peer review process.

\section{G. Learning Experience and Instruction}

E-Learning is not always suitable for all modules; sometimes human interactions in the physical environment can be more conducive to incentivizing student learning. This certificate will be delivered part time on one or two nights per week from $6 \mathrm{pm}$ until $10 \mathrm{pm}$ across an academic year. This permits students to more easily make a manageable commitment to this certificate. All modules are lecture-based and lab-based, all lectures will be delivered from 6 pm until $8 \mathrm{pm}$ and all labs will run from 8:30 pm until $10 \mathrm{pm}$. The subsequent lab session will demonstrate to students how to use technologies to enhance the skills learned in the lecture room and will show students how to apply proper skills to bridge theories and real-life applications. All activities in lab and lecture will be recorded as live sessions so that students can revisit the material anytime they wish. The students on 
this certificate are not expected to have extensive IT skills.

To ensure that all students are appropriate for this certificate, a prior knowledge test for each module will be held a week before the term commences. According to the results of prior knowledge tests, lecturers will adjust the content to be delivered without any modifications to the syllabus of each module.

To ensure an alignment between what a certificate aims to achieve and what students actually learn, [22] highlighted that how a programme is taught and assessed should be discussed and defined at the design phase. [23] suggests that students do not pay attention continuously for more than 10-20 minutes during a lecture. [24] suggested a lecturer should pause periodically and have students clarify their notes with a partner. This pause procedure might retain students' engagement when their minds start to wander. Lecturers on this certificate will be encouraged to employ class participation and active learning principles throughout their lectures to enhance the learning process.

\section{H. Curriculum Mapping}

The curriculum map for this certificate is presented in table I. This curriculum map clearly indicated that the concepts related to the third PLO are strongly emphasized by all modules in this certificate; concepts related to the first PLO are introduced by all modules in this certificate. Compared to the other two modules, the fundamental problem-solving skills module strongly supports most of the PLOs.

\section{CURriculum Evaluation}

There are four different curriculum evaluation models. Kirkpatrick's assessment model [25] is widely used in most educational and technical training sessions. This model addresses the need of training professionals to understand training evaluation in a systematic way [26]. It presents an oversimplified view of training effectiveness that does not consider individual or contextual influences in the evaluation of training. The CIPP model [27] can be used to effectively evaluate the quality of education at a university. It can be used for both summative and formative evaluations.

TABLE I: A CURRICULUM MAP FOR THIS CERTIFICATE

\begin{tabular}{|c|c|c|c|}
\hline \multirow{2}{*}{$\begin{array}{c}\text { PLO } \\
\text { s }\end{array}$} & \multicolumn{3}{|c|}{ Programme Modules } \\
\cline { 2 - 4 } & $\begin{array}{c}\text { Academic } \\
\text { Writing for } \\
\text { Novices }\end{array}$ & $\begin{array}{c}\text { Introduction to } \\
\text { Plagiarism }\end{array}$ & $\begin{array}{c}\text { Fundamental } \\
\text { Problem-Solvin } \\
\text { PLO1 }\end{array}$ \\
\hline PLO2 & $\mathrm{X}$ & $\mathrm{X}$ & gkills \\
\hline PLO3 & $\mathrm{XXX}$ & $\mathrm{X}$ & $\mathrm{X}$ \\
\hline PLO4 & $\mathrm{X}$ & $\mathrm{XXX}$ & $\mathrm{XXX}$ \\
\hline PLO5 & $\mathrm{X}$ & $\mathrm{X}$ & $\mathrm{X}$ \\
\hline
\end{tabular}

It provides a holistic view of every element by evaluating context, input, process and output from each and every angle. [28] noted that it seems difficult to implement and expensive to maintain. The Tuning Checklist model [29] considers the educational process, the educational outcome, and the means and facilities required. Eisner's Connoisseurship model [30] emphasizes qualitative appreciation. This framework broadens the evaluator's perspective and enriches his/her repertoire. Its critics have faulted it for its lack of methodological rigor and because it requires a great deal of expertise.

We will employ the CIPP model to evaluate our certificate.

\section{A. Context Evaluation}

As most freshmen, administrative staff and technicians who work in third-level education lack fundamental academic skills, it is necessary to establish a separate programme in the institution to assist those learners to boost their confidence and competence in the application of those skills. Particularly, it assists freshmen in progressing more easily through the rest of their four years of college study. Hence, it should not be integrated with other programmes. It should be established as a standalone bridging programme. This certificate should highly correlate with students' success in progressing past the first-year level 7 and level 8 programmes in different fields.

\section{B. Inputs}

This certificate is available to all learners from different backgrounds. To retain a consistent level for this certificate, a prior knowledge test for each module will be needed. Before any formal release of this certificate, it would be valuable to gain some perspectives from all staff in the institution. Surveys are the normal approach to gathering information from a large number of different people. A survey would be conducted for all staff in the institution. In this survey, we hopefully can gain some insight into the adequacy of this proposed certificate querying issues such as "Are all PLOs suitable?". Another important resource will be conducting a survey of all students participating in the retention programme, those that have dropped out, and those that have failed to progress to another level.

This certificate will be offered as a part-time evening programme so that it does not collide with the schedules of daytime courses. The most important factor will be the availability of professional lecturers with a special accreditation to deliver the modules. We will need a lecturer possessing an international EAP teaching qualification and another lecturer who is an influential academic researcher in this area. This researcher should have expertise in academic ethics and strong problem-solving skills and, (s)he should have strong pedagogical knowledge and good teaching skills. Based on this analysis, we may need two to three lecturers to deliver the modules. This programme is not intended to be delivered to a large classroom. The maximum class size would be 20. All lecturers will be expected to adopt active learning, formative feedback, and problem-based teaching skills to create an interactive learning environment for learners. 


\section{Process}

Modules should be designed not only with students' needs in mind but also with those of the lecturers concerned. Lecturers should be encouraged to approach the course coordinator during the delivery with feedback on the certificate and lecturers should be contacted at the end of their module delivery looking for comprehensive feedback. Lecturers can use online survey tools to collect student feedback at the modular level.

The outcome of these conducted surveys and gathered feedback will be very helpful and valuable for the programmatic review meeting. In the programmatic review, the panel will monitor and control the quality of this certificate and make further enhancements. Another significant feedback measure will be the number of students who have enrolled in this certificate; the figure will provide a strong indication of the importance of this certificate to the programmatic review panel. Once the certificate is officially delivered, it will be the programme coordinators' responsibility to monitor the performance of the certificate. (S)he should deliver a programme monitoring report annually. The programme coordinator should take external examiners' opinions and feedback into serious consideration when (s)he makes any further amendments. These external examiners should be sourced with an eye as to their expertise in this field.

\section{Product}

After the completion of this certificate, it is mandatory for all learners to retake the prior knowledge test for each module to evaluate whether learners have made an improvement in these modules. Moreover, a survey should be administered to the first student cohort to see what learning and basic academic skills have been gained, what motivated students to sign up to this certificate, and any suggestions on possible improvements to this certificate. We will need to conduct another survey for all lecturers who deliver second year level 7 or level 8 programmes to see if there are any academic improvements to the performance of those students who completed this certificate. It will be vital to constantly gather feedback and conduct surveys to, through constant review and evaluation, help guarantee the survival of this certificate. The result of review and evaluation could also guide the development of this certificate - suggesting appropriate expansions or upgrades to this certificate. Nevertheless, we will need to constantly review the certificate and benchmark ourselves against similar competing programmes globally and nationally.

\section{CONCLUSION}

This paper has charted the development of a new certificate, entitled a Certificate in Academic Skills, which is a HETAC special purpose award at level 6. A curriculum design model, the backward design model, was exploited to develop this certificate. At the start of this development process, the programme ethos was clearly articulated. According to this ethos, a set of standardized PLOs was outlined. Applying Bigg's CA concept, sets of module Los, assessments, and the teaching activities of each module are properly aligned with preset PLOs. These assessment strategies, teaching activities and curriculum map validate this programme. Finally, this certificate was evaluated using the CIPP evaluation model This systematic approach has developed a programme capable of being delivered to all stakeholders. Should the programme be implemented by CIT, it would have to progress through the programme approval process. This process would require the addition of more detail relating to delivery mechanisms and institutional regulations and guidelines.

We are confident that the programme would stand up to further scrutiny and examination. During this process, we have gained knowledge and a better insight into how to create a proper programme in a university. We believe that different universities will have different policies and guidelines on setting up new programmes; however, the basic principles and the theories will never change. This certificate is very vocational. Thus far CIT has not employed any standard curriculum evaluation models. It is an interesting open question as to whether the deployment of such curriculum evaluation models would enhance the quality of programmes in CIT or whether the hybridization of a curriculum evaluation model with the current CIT evaluation system would make any positive impact. It will be even more intriguing to see if we can utilize the whole process of curriculum evaluation to better gauge the value of this certificate and how and where this certificate might need to be enhanced. All these uncertainties and unanswered questions will inspire us to further study and investigation in this field.

\section{CONFLICT OF INTEREST}

"The author, Jing Hua Ye, declare no conflict of interest".

\section{AUTHOR CONTRIBUTIONS}

The whole paper is an individual work. Jing Hua Ye has conducted the full research and all tasks for producing this paper.

\section{REFERENCES}

[1] J. S. Atherton. (2010). Learning and Teaching: Curriculum. [Online]. Available: http://www.learningandteaching.info/teaching/curriculum.htm

[2] A. V. Kelly, The Curriculum. Theory and Practice, London: Paul Chapman, 1999.

[3] C. R. Finch and J. R. Crunkilton, "Curriculum development in vocational and technical education: Planning, content, and implementation," Allyn and Bacon, Boston, 1999.

[4] K. Dunbar, "The curriculum," Skills Development through Distance Education, The Commonwealth of Learning, Vancouver, 2002.

[5] R. W. Tyler, "Basic principles of curriculum and instruction," Chicago, IL, and London: The University of Chicago Press, 1949.

[6] G. O’Neill, "Programme design," Dublin: UCD Teaching and Learning, 2010.

[7] G. Wiggins and J. McTighe, "Understanding by design: A brief introduction," Center for Technology \& School Change at Teachers College.

[8] H. S. Barrow, "A taxonomy of problem-based learning methods," IEEE Trans. Image Process, vol. 10, no. 5, pp. 767-782, May 2001

[9] R. M. Branch, "Instructional design: The ADDIE approach," vol. 722, Springer Science \& Business Media, 2009.

[10] W. Dick, L. Carey, and J. O. Carey, "The systematic design of instruction," Boston, MA: Allyn and Bacon, 1937.

[11] Ramsden, "Learning to teach in higher education," 2nd Edition, RoutledgeFalmer, 2003. 
[12] G. Gibbs and C. Simpson, "Conditions under which assessment supports students' learning," Learning and Teaching in Higher Education, vol. 1, pp. 3-33, 2004.

[13] S. Brown, "Assessment for learning," Learning and Teaching in Higher Education, vol. 1, pp. 81-89, 2004.

[14] CoRe, "A tuning guide to formulating degree programme profiles including programme competences and programme learning outcomes," 2010.

[15] B. S. Bloom, M. D. Engelhart, E. J. Furst, W. H. Hill, and D. R. Krathwohl, "Taxonomy of educational objectives Handbook 1: cognitive domain,” London, Longman Group Ltd, 1956.

[16] L. W. Anderson and D. R. Krathwohl, "A taxonomy for learning, teaching and assessing: A revision of Bloom's Taxonomy of educational objectives," New York: Longman, 2001.

[17] S. Bloxham and P. Boyd, "Developing effective assessment in higher education: A practical guide," Open University Press, 2007.

[18] Geraldine O'Neill, "UCD assessment ReDesign project: The balance between assessment for and of learning," 2012.

[19] P. Black and D. Williams, "Assessment and classroom learning," Assessment in Education, vol. 5, no. 1, pp. 7-74, 1998.

[20] J. B. Biggs, "Enhancing teaching through constructive alignment," Higher Education, vol. 32, no. 3, pp. 347-364, 1996.

[21] C. Rust, M. Price, and B. O'Donovan, "Improving students' learning by developing their understanding of assessment criteria and processes," Assessment and Evaluation in Higher Education, vol. 28, no. 2, pp. 147-164, 2003

[22] A. Pollard and P. Triggs, Reflective Teaching in Secondary Education, London: Continuum, 1997.

[23] K. Y. Neiles et al., "How long can students pay attention in class? A study of student attention decline using clickers," Journal of Chemical Education, vol. 87, no. 12, pp. 1438-1443, 2010.

[24] P. Michael, "Does active learning work? A review of the research," Journal of Engineering Education, vol. 93, no.3, pp. 1-9, 2004
[25] D. L. Kirkpatrick and J. D. Kirkpatrick, Evaluating Training Programs: The Four Levels, San Francisco, CA: BerrettKoehler Publishers, 2006.

[26] S. Shelton and G. M. Alliger, "Who's afraid of level 4 evaluation? A practical approach," Training and Development Journal, vol.47, pp.43-46, 1993.

[27] D. L. Stufflebeam, "The CIPP model for evaluation," The International Handbook of Educational Evaluation, Boston, MA: Kluwer Academic Publishers, 2003.

[28] E. Guba and Y. Lincoln, Effective Evaluation, San Francisco: Jossey-Bass, 1981.

[29] Tuningeu.

[Online].

Available: http://www.unideusto.org/tuningeu/images/stories/quality/QUALITY ENHANCEMENT__ANNEX_2.pdf

[30] E. W. Eisner, The Educational Imagination: On the Design and Evaluation of School Programs, New York: Macmillan, 1979.

Copyright $\odot 2019$ by the authors. This is an open access article distributed under the Creative Commons Attribution License which permits unrestricted use, distribution, and reproduction in any medium, provided the original work is properly cited (CC BY 4.0).

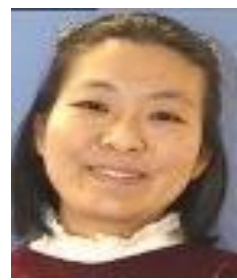

Jing Hua Ye received a BSc degree and MSc degree (by research) in computer science from University College Cork. She joined the Cork Institute of Technology in 2012 where she is working as an assistant lecturer in the Computer Science Department. She recently received a certificate in teaching and learning in higher education and is now pursuing further studies in third-level teaching and learning practices via a postgraduate diploma in teaching and learning. Her personal research interests are in the fields of machine learning, optimization, and big data analysis. 